\title{
Inclusão em foco: um estudo de caso sobre um deficiente que possui surdocegueira no ensino regular
}

Inclusion in focus: a case a study about a deficient that have deafblindness in the regular education

Inclusión en foco: un estudio de caso sobre un discapacitado que tiene sordocegueira en la enseñanza regular

\section{* Luiza Liene Bressan}

Professora da Fundação Educacional Barriga Verde, Orleans, Santa Catarina, Brasil. luizalbc@yahoo.com.br

\section{** Beatriz Schueroff Buss}

Mestranda pela Universidade do Extremo Sul Catarinense, Criciúma, Santa Catarina, Brasil. beatriz_buss@hotmail.com

\section{** Alexandra Aline Lewcowicz}

Mestre em Fonoaudiologia pela Universidade de Santa Maria, Santa Maria, Rio Grande do Sull, Brasil abfono@yahoo.com.br

Recebido em 19 de abril de 2017

Aprovado em 18 de setembro de 2018

Publicado em 06 de maio de 2019

\section{RESUMO}

O presente trabalho aborda o seguinte tema: Inclusão em foco: um estudo de caso sobre uma pessoa com deficiência que possui surdocegueira no ensino regular. Quando se enfatiza esta temática, tem-se interesse no estudo sobre a inclusão das pessoas com deficiencia, assim, a questão primordial, é buscar conhecer como ocorre o processo de inclusão de uma criança surdocega no ensino regular. Para isso estabelecemos como objetivos deste estudo: compreender o processo de inclusão de uma criança com surdocegueira no ensino regular; fazer um breve estudo da trajetória histórica da deficiência, verificando de que forma se dá o processo de inclusão no ensino regular. $A$ pesquisa é do tipo descritivo com estudo de caso. Utilizou-se como instrumento de coleta de dados um questionário e as respostas foram analisadas, confrontando os aspectos teóricos da inclusão e a realidade escolar. A pesquisa apontou alguns resultados que merecem maiores reflexões, pois ainda há resistência por parte dos docentes quando 0 tema é inclusão. A mudança precisa acontecer no ambiente escolar para que ela se torne de fato uma realidade e não apenas um ato legal.

Palavras-chave: Inclusão; Surdocegueira; Ensino regular. 


\section{ABSTRACT}

The present work approaches the following theme: Inclusion in focus: a study of in case on a deficient one that it possesses deafblindness in the regular teaching. When this theme is emphasized has is interested in the study on the inclusion of the people with deficiency. Like this, the research problem is to look for to know how it happens the process of a child's inclusion deaf-blinds in the regular teaching. For that we established as objectives of this study: to Understand the process of a child's inclusion deaf-blinds in the regular teaching; to do an abbreviation study of the historical path of the deficiency, verifying that it forms if he/she gives the inclusion process in the regular teaching; to study the concept of deafblindness, contemplating of the teaching process and a child's learning with special needs; to Identify the historical path of the deficiency, verifying that it forms if he/she gives the inclusion process in the regular teaching; to study the concept of deaf-blindness, contemplating of the teaching process and a child's learning with special needs; to appear through the research that it forms if gives the process of a deaf-blind student's teaching learning in school atmosphere; to show through worked activities the evolution of the deafblind student's process teaching learning without verbal communication until the moment in the school atmosphere where is inserted and to write through the accomplished studies them forms that it happens the inclusion process and the organization of the process of teaching learning for a child with deaf-blindness in the research atmosphere. The used method is the monographic and the research is of the applied type with case study. It was used as data collection instrument a questionnaire and the answers were analyzed, confronting the theoretical aspects of the inclusion and the school reality.

Keywords: Inclusion; Multiple deficiency; Deafblindness

\section{RESUMEN}

El presente trabajo aborda el siguiente tema: Inclusión en foco: un estudio de caso sobre una persona con discapacidad que tiene sordocegueira en la enseñanza regular. Cuando se enfatiza esta temática, se tiene interés en el estudio sobre la inclusión de las personas con discapacidad, así, la cuestión primordial, es buscar conocer cómo ocurre el proceso de inclusión de un niño sordocega en la enseñanza regular. Para ello establecemos como objetivos de este estudio: comprender el proceso de inclusión de un niño con sordocegueira en la enseñanza regular; hacer un breve estudio de la trayectoria histórica de la discapacidad, verificando de qué forma se da el proceso de inclusión en la enseñanza regular. La investigación es del tipo descriptivo con estudio de caso. Se utilizó como instrumento de recolección de datos un cuestionario y las respuestas fueron analizadas, confrontando los aspectos teóricos de la inclusión y la realidad escolar. La investigación apuntó algunos resultados que merecen mayores reflexiones, pues aún hay resistencia por parte de los docentes cuando el tema es inclusión. El cambio debe ocurrir en el ambiente escolar para que se convierta de hecho en realidad y no sólo un acto legal.

Palabras clave: Inclusión; sordoceguera; Enseñanza regular. 


\title{
Introdução
}

A Educação é um processo em constante transformação. Se a sociedade se transforma, a educação precisa acompanhar os processos de mudança. Por seu caráter social, os processos educativos são dinâmicos e visam atender as inovações inerentes ao desenvolvimento, principalmente os da tecnologia da informação que aceleram todos os processos sociais e econômicos. Assim, pela educação é possível formar pessoas melhores e instruídas que poderão compreender a formação humana de maneira mais ampla, procurando desenvolver todas as suas potencialidades. A partir deste cenário é que, atualmente, discute-se muito sobre a inclusão das pessoas com deficiência, intelectual, mental, auditiva, física, visual, deficiências múltiplas e portadores de altas habilidades, mas o objetivo principal é para todo o foco da inclusão.

\begin{abstract}
A educação inclusiva é uma ação política, cultural, social e pedagógica, desencadeada em defesa do direito de todos os alunos de estarem juntos, aprendendo e participando, sem nenhum tipo de discriminação. A educação inclusiva constitui um paradigma educacional fundamentado na concepção de direitos humanos, que conjuga igualdade e diferença com valores indissociáveis. (POLÍTICA NACIONAL DE EDUCAÇÃO ESPECIAL NA PERSPECTIVA DA EDUCAÇÃO INCLUSIVA, 2007, p.11).
\end{abstract}

"Uma ação educativa comprometida com cidadania e com a formação de uma sociedade democrática e não excludente deve, necessariamente, promover o convívio com a diversidade, o que é uma marca social brasileira". (RCNEI, 1998.p.35). Porém a diversidade não se trata somente de diversidade de culturas, mas também das particularidades e competências especificas de cada indivíduo, sejam elas pessoas ditas como "normais" pela sociedade ou as pessoas "deficientes" como são taxadas nos dias atuais.

Assim, o problema que norteou este estudo foi o de responder ao seguinte questionamento: como ocorre o processo de inclusão de uma criança com surdocegueira no ensino regular? E para responder a esta questão-problema foram estabelecidos como objetivos: compreender o processo de inclusão de uma criança surdocega no ensino regular; estudar a trajetória histórica da deficiência, verificando de que forma se dá o processo de inclusão no ensino regular; estudar o conceito de surdocegueira, refletindo do processo de ensino e aprendizagem de uma criança com necessidades especiais; apontar por meio da pesquisa de que forma se deu o processo de ensino aprendizagem de um aluno surdocego no seu ambiente escolar; analisar sob o viés dos educadores de uma escola como acontece a inclusão de um aluno surdocego no ensino regular. 
Como base no Referencial Curricular Nacional para a Educação Infantil (1998. p.36), "a Educação Especial, termo cunhado para educação dirigida às pessoas deficientes, de condutas típicas e altas habilidades, é considerada pela Constituição Brasileira, como parte inseparável do direito à educação". O grande desafio da Escola Inclusiva é desenvolver uma pedagogia centrada na criança, capaz de educar a todas, discriminação e respeitando sempre as diferenças de cada um.

Entre os vários casos de inclusão que encontramos em ambientes escolares um dos que podemos citar é a inclusão das pessoas com surdocegueira.

Por meio de um processo e contato com um aluno surdocego no ambiente escolar, sua evolução no processo de aquisição de fala e também no processo de ensino aprendizagem levou à escolha do seguinte tema: Inclusão em Foco: Um estudo de caso sobre um deficiente que possui surdocegueira no ensino regular.

O termo surdocego designa às pessoas que apresentam a perda total ou até mesmo parcial dos sentidos da audição e visão. Conforme Lagati (1995, p. 306):

Surdocegueira é uma condição que apresenta outras dificuldades além daquelas causadas pela cegueira e pela surdez. $O$ termo hifenizado indica uma condição que somaria as dificuldades da surdez e da cegueira. A palavra sem hífen indicaria uma diferença, uma condição única e o impacto da perda dupla é multiplicativo e não aditivo.

Traz-se o grande interesse pelo estudo sobre o tema citado acima, desta forma darse-á o desenvolvimento de um trabalho de conclusão de curso com a intensão de demostrar por meio da pesquisa o trabalho, as atividades e os estudos realizados sobre a inclusão do surdocego, para que haja um melhor entendimento e compreensão de todos.

\section{Breve Histórico das Deficiências}

Desde os primeiros tempos, as pessoas consideradas deficientes vêm trazendo uma maior repercussão perante a sociedade porque o nível de curiosidade em relação a elas aumentou, tendo assim um maior interesse sobre o assunto. Chama atenção do meio social porque se acredita que os sujeitos podem ter uma padronização, ser "normalizados", então passamos a chamar estes indivíduos que não se encaixam neste padrão de "deficientes", pois Ihe faltam algumas características que tornam a maioria das pessoas normais.

De acordo com Vargas, (2003. p.29), em alguns momentos da história, essa mesma sociedade procurou exterminar as pessoas consideradas deficientes, já em outros momentos, quis institucionalizar a deficiência e, mais recentemente, tem lançado mão de categorização para confirmar sua própria normalidade. 
http://dx.doi.org/10.5902/1984686X24891

As raízes históricas e culturais do fenômeno deficiência sempre foram marcadas por forte rejeição, discriminação e preconceito. A literatura da Roma Antiga relata que as crianças com deficiências, nascidas até o princípio da era cristã, eram afogadas por serem consideradas anormais e débeis. $\mathrm{Na}$ Grécia antiga, a crianças mal constituídas ou deficientes eram sacrificadas ou escondidas pelo poder público (BRUNO, 2006.p.9).

Historicamente, percebe-se a rejeição das pessoas deficientes, não somente no período da antiguidade, mas até mesmo na Idade Média as pessoas com deficiências mentais, ou também conhecidas na época como loucos, eram considerados possuídos pelo demônio e, por isso, eram excluídos da sociedade. Já os cegos e surdos eram atribuídos os poderes e dons sobrenaturais. Na trajetória podem-se encontrar as explicações dos filósofos cristãos, que diziam que oscilava entre culpa e expiação de pecado.

\section{Inclusão: uma narrativa em construção}

Em uma antiguidade pautada pela perfeição ideal, as pessoas com deficiência eram eliminadas. Em seguida, foram consideradas incapazes e, posteriormente, deficientes. Durante o nazismo, os assassinatos recomeçaram não mais baseados na cultura, mas sim na vontade de purificar a raça. Mesmo com tantos obstáculos alguns ainda conseguiram alcançar o direito de serem cidadãos.

Então, para assegurar o direito de todos para educação pública e gratuita, as Políticas Públicas foram alcançadas em 1948 em que foi feita e Declaração dos Direitos Humanos. "A proposta de integração segundo a qual o sujeito deveria adaptar-se a sociedade" (SANTA CATARINA- UDESC, 2003, p.65).

Os movimentos mundiais de integração das pessoas com deficiência defendiam as oportunidades educacionais e sociais iguais para todos, o que contribuiu muito para a criação dos serviços de educação especial e classes especiais em escolas públicas no Brasil. Dessa forma, surge a Lei de Diretrizes e Bases da Educação Nacional (Lei № 4.024/61), com a recomendação de integrar, no sistema geral de ensino, a educação de excepcionais, como eram chamados na época às pessoas com deficiência.

\section{Surdez: aspectos clínicos e aprendizagem}

A audição é um dos sentidos sensoriais que o ser humano possui, mas algumas pessoas nascem desprovidas deste sentido ou perdem ao longo da vida. A falta dele é considerada como deficiência auditiva, ou seja, uma perda na capacidade de perceber sons. Esta perda pode ser tanto parcial, como total em alguns casos.

De acordo com a Resolução № 112: 
http://dx.doi.org/10.5902/1984686X24891

Deficiência auditiva é a perda parcial ou total, congênita ou adquirida da capacidade de compreender a fala através do ouvido. A mensuração é feita através de avaliações que comprovem perda bilateral de 25 decibéis $(\mathrm{dB})$ ou mais, resultante da aritmética do audiograma, aferida nas frequências de 500 Hertz (Hz), $1000 \mathrm{~Hz}, 3000 \mathrm{~Hz}, 4000 \mathrm{~Hz}$; variando de acordo com o nível de acuidade auditiva da seguinte forma: leve/moderada: perda auditiva de 25 a $70 \mathrm{~dB}$; severa/ profunda: perda auditiva acima de $71 \mathrm{~dB}$. (FLORIANÓPOLIS, 2006, p.1)

A comunicação humana é imprescindível, pois é dessa forma que nos expressamos, emocionamos, transmitimos e recebemos informações, a linguagem é indissociável do ser humano e o acompanha em sua trajetória de vida. É o instrumento ao qual o homem modela seu pensamento, sua vontade e seus atos, influencia e é influenciado, fundamento essencial e mais profundo da sociedade humana. Assim, em comunidades surdas a comunicação também é de fundamental importância para que haja interação. Como exemplo, Lima (2006) cita que existem pessoas surdas que se comunicam com a Língua Brasileira de Sinais-Libras. Foi legalizada no Brasil através da Lei № 10.436, em abril de 2002, que dispõe e reconhece a Libras- Língua Brasileira de Sinais como meio legal de comunicação e expressão objetiva e de utilização de corrente das comunidades surdas do Brasil. E também temos as pessoas que se comunicam e oralizam ou leitura labial.

Ainda, para Lima (2006, p.23), "A criança deficiente auditiva seja qual for a sua perda, também devem ser inclusa nas redes regulares de ensino". Entretanto, há diferenciação entre a inclusão do surdo leve e moderado para o surdo profundo. A inclusão de uma criança com surdez leve e moderada pode ser feita de forma natural nas creches e préescolas em que a língua portuguesa é a língua de comunicação. Já o surdo profundo, deve ter acompanhamento em uma sala de recursos para aquisição e apropriação de LIBRAS para desenvolvimento da língua portuguesa escrita.

\section{Cegueira: Um Mundo cuja Imagem é Sentida, não Percebida}

A visão tem um reinado soberano ao estabelecer um contato com o mundo exterior, facilitando o intercâmbio comunicativo desde os primeiros meses de vida. A criança com cegueira não efetua essa interação, dificultando o desenvolvimento das habilidades ligadas a este órgão sensorial, pois "a cegueira é uma alteração grave ou total de uma ou mais das funções elementares da visão que afeta de modo irremediável a capacidade de perceber cor, tamanho, distância, forma, posição ou movimento em um campo mais ou menos abrangente" (SÁ et al, 2007, p.15). 
Além da cegueira, há também aqueles que possuem baixa visão que conforme (Sá et al, 2007, p.16):

A definição de baixa visão (ambliopia, visão subnormal ou visão residual) é complexa devido à variedade e à intensidade de comprometimentos das funções visuais. Essas funções englobam desde a simples percepção de luz até a redução da acuidade e do campo visual que interferem ou limitam a execução de tarefas e o desempenho geral. Em muitos casos, observa-se o nistagmo, movimento rápido e involuntário dos olhos, que causa uma redução da acuidade visual e fadiga durante a leitura.

Essas limitações, no entanto, podem ser minimizadas e a aprendizagem e desenvolvimento da criança podem ser estimulados a partir da utilização do Sistema Braille para ler e escrever e, também, do auxílio de informática. Os sentidos do tato, da audição, do olfato e do paladar assimilam as informações procedentes dos estímulos externos, que ao serem integradas, possibilitam a percepção, análise e compreensão do ambiente.

De acordo com o Decreto № 5.296 (Brasília, 2004, p.2):

Deficiência visual: cegueira, na qual a acuidade visual é igual ou menor que 0.05no menor olho, com a melhor correção óptica; a baixa visão, que significa acuidade visual entre 0.3 e 0.05 no melhor olho, com a melhor correção óptica; os casos nos quais a somatória da medida do campo visual em ambos os olhos for igual ou menor que 60, ou a ocorrência simultânea de quaisquer das condições anteriores.

Segundo Bruno, (1997 p.7) "Os portadores de cegueira são aqueles que possuem ausência total de visão até a perda da projeção da luz".

O processo de leitura e escrita dar-se-á pelo sistema Braille. Entre essas crianças, há aquelas que não enxergam e outras que têm uma percepção de luz, algumas podem perceber o claro, o escuro e delinear algumas formas. A mínima percepção de luz ou de vulto pode ser muito útil para orientação no espaço, movimentação e habilidades de independência (BRUNO, 2006. p. 13).

O deficiente visual é aquele que apresenta redução ou perda total da capacidade de ver com o melhor olho e após a melhor correção óptica.

De acordo com Sá, Campos e Silva (2007), cegueira é uma alteração grave ou total de uma ou mais funções elementares da visão que afeta de modo irremediável a capacidade de perceber cor, tamanho, distância, forma, posição ou movimento em um campo mais ou menos abrangente.

\section{Deficiência Múltipla}

O termo deficiência múltipla tem sido utilizado com frequência para caracterizar o conjunto de duas ou mais deficiências associadas, sejam elas de ordem física, sensorial, 
mental, emocional ou de comportamento social. No entanto, não se caracteriza em um somatório dessas alterações, mas sim o grau de desenvolvimento, as possibilidades de funcionais, de comunicação, alteração social e de aprendizagem que determinam as necessidades educacionais dessa pessoa.

De acordo com a Resolução nº 112 (Florianópolis, 2006, p.2) “Deficiência Múltipla é a associação de duas ou mais deficiência primárias, sejam elas na área mental, visual, auditiva ou física".

São consideradas pessoas com deficiência múltipla aquelas que "têm mais de uma deficiência associada. É uma condição heterogênea que identifica diferentes grupos de pessoas, revelando associações diversas de deficiências que afetam, mais ou menos intensamente, o funcionamento individual e o relacionamento social" (MEC/SEESP, 2002).

\section{A inclusão do deficiente surdocego no ensino regular}

As pessoas com algum tipo deficiência possuem suas limitações e dificuldades, sejam de ordem física, sensorial, mental, emocional ou de comportamento social. No entanto, não é o somatório dessas alterações que caracteriza a deficiência múltipla, mas sim o grau de desenvolvimento, as possibilidades funcionais, de comunicação, interação social e de aprendizagem que determinam as necessidades educacionais dessas pessoas.

De acordo com Godói (2006, p. 13):

Os alunos com deficiências múltiplas podem apresentar alterações significativas no processo de desenvolvimento, aprendizagem e adaptação social. Possuem variadas potencialidades, possibilidades funcionais e necessidades concretas que necessitam ser compreendidas e consideradas. Apresentam, algumas vezes, interesses inusitados, diferentes níveis de motivação, formas incomuns de agir, comunicar e expressar suas necessidades, desejos e sentimentos.

A inclusão desses alunos no sistema regular de ensino é desejada por famílias, escolas e professores solidários que se propõem a assumir desafios. As escolas que tem obtido êxito no processo de inclusão adotam como compromisso o respeito a diversidade e diferenças individuais, a adaptação do currículo e a modificação dos recursos metodológicos e do meio. Esses são fatores são essenciais e capazes de atender as necessidades específicas de aprendizagem desses educandos.

\section{Procedimentos Metodológicos}

Quanto à natureza da abordagem da presente pesquisa, pode-se dizer que foi de caráter aplicado, porque além de buscar na literatura autores renomados que enfatizam o 
presente tema, a sua prática se deu em uma Instituição Municipal que atende o aluno que foi pesquisado. Esta instituição está situada no centro da cidade.

Sob o ponto de vista da abordagem do problema, a referida pesquisa é nominada como quantitativa, porque os resultados obtidos na pesquisa são apresentados em forma de quadros e percentuais, e descritiva, pois estes dados são confrontados com os aspectos teóricos estudados. De acordo com Marconi e Lakatos (2010) a pesquisa quantitativa é aquela em pode ser mensurada em números, classificada e analisada.

Sobre os procedimentos técnicos, a pesquisa realizada na instituição caracterizou-se como estudo de caso, pois foi estudado apenas um sujeito.

Como instrumento de coleta de dados foi utilizado um roteiro de pesquisa com dez questões elaboradas de forma objetiva/subjetiva com intuito de responder ao processo de desenvolvimento e aprendizagem do aluno com surdocegueira em estudo no momento.

\section{Resultados e Discussão}

Passamos, então, a analisar as respostas obtidas na pesquisa realizada com os professores que atuam na Escola Municipal Prof. José Boeing de Rio Fortuna- SC. São profissionais que atendem crianças de 4 anos (pré-escolar) até 10 anos ( $5^{\circ}$ ano). Também participaram os gestores da escola: diretor, coordenadora pedagógica e a secretária municipal de educação.

Quadro 1- Inclusão, um processo de aprendizagem?

\begin{tabular}{|l|l|l|}
\hline Código & Número de respostas & Porcentagem \% \\
\hline Concordo totalmente & 3 pessoas & $14 \%$ \\
\hline Concordo & 14 pessoas & $66 \%$ \\
\hline Concordo parcialmente & 4 pessoas & $19 \%$ \\
\hline Discordo totalmente & Nenhuma resposta & $0 \%$ \\
\hline Discordo & Nenhuma resposta & $0 \%$ \\
\hline Discordo Parcialmente & Nenhuma resposta & $0 \%$ \\
\hline
\end{tabular}

Fonte: Dados da pesquisa, 2015.

O primeiro quadro de respostas traz a informação que a maioria dos entrevistados (66\%) concorda que a inclusão é um processo de aprendizagem, 14\% concordam plenamente e 19\% concordam parcialmente. Tais resultados nos levam a refletir que o processo de inclusão ainda não está totalmente compreendido no contexto da escola investigada.

A educação inclusiva deve ter como ponto de partida o cotidiano: o coletivo, a escola e a classe comum, onde todos os alunos com necessidades educativas, especiais ou não, precisam aprender ter acesso ao 
http://dx.doi.org/10.5902/1984686X24891

conhecimento, à cultura e progredir no aspecto pessoal e social. (BRUNO, 2006 p.14).

Quadro 2- Inclusão um processo de aceitação?

\begin{tabular}{|l|l|l|}
\hline Código & Número de respostas & Porcentagem \% \\
\hline Concordo totalmente & 4 pessoas & $19 \%$ \\
\hline Concordo & 9 pessoas & $43 \%$ \\
\hline Concordo parcialmente & 2 pessoas & $9,5 \%$ \\
\hline Discordo totalmente & Nenhuma resposta & $0 \%$ \\
\hline Discordo & 5 pessoas & $24 \%$ \\
\hline Discordo Parcialmente & Nenhuma resposta & $0 \%$ \\
\hline
\end{tabular}

Fonte: Dados da pesquisa, 2015.

No segundo quadro encontramos uma grande diversidade de respostas que $43 \%$ das pessoas responderam que concordam que a inclusão é um processo de aceitação, 19\% concordam totalmente e 9,5\% concordam, mas parcialmente. Outros $24 \%$ das pessoas responderam que discordam desse processo. Novamente podemos perceber que a ideia de inclusão ainda não é aceita para esses profissionais da educação.

Da mesma forma como o professor não conhece nenhum de seus alunos, ele também não conhece aquele com deficiência, então o primeiro passo é criar vínculo, se aproximar, conhecê-lo, questionar e refletir sobre as características individuais (BAPTISTA s/d. p.06).

Quadro 3 - Todos os profissionais da educação estão preparados para incluir alunos com deficiência?

\begin{tabular}{|l|l|l|}
\hline Código & Número de respostas & Porcentagem \% \\
\hline Concordo totalmente & Nenhuma resposta & $0 \%$ \\
\hline Concordo & Nenhuma resposta & $0 \%$ \\
\hline Concordo parcialmente & Nenhuma resposta & $0 \%$ \\
\hline Discordo totalmente & 6 pessoas & $28.5 \%$ \\
\hline Discordo & 8 pessoas & $38 \%$ \\
\hline Discordo Parcialmente & 7 pessoas & $33 \%$ \\
\hline
\end{tabular}

Fonte: Dados da pesquisa, 2015.

No terceiro quadro de respostas mostra que 28,5\% das pessoas discordam totalmente, dizendo que os profissionais da educação não estão preparados para incluir alunos com deficiência, já 38\% discordam e 33\% discordam parcialmente. Assim está visível à falta de preparo dos profissionais da educação para realizar o processo de inclusão.

Para atuar na educação especial, o professor deve ter como base a formação, inicial e continuada, conhecimentos gerais para o exercício da docência e conhecimentos específicos da área. (Política Nacional Educação Especial Perspectiva da Educação Inclusiva, 2007, p. 11). 
http://dx.doi.org/10.5902/1984686X24891

Quadro 4 - Entre as deficiências, há aquelas chamadas de Múltiplas. Dessa forma, o aluno deficiente em seu processo de aprendizagem demora mais tempo para aprender do que os demais considerados "normais"?

\begin{tabular}{|l|l|l|}
\hline Código & Número de respostas & Porcentagem \% \\
\hline Concordo totalmente & 2 pessoas & $9,5 \%$ \\
\hline Concordo & 14 pessoas & $66 \%$ \\
\hline Concordo parcialmente & 3 pessoas & $14 \%$ \\
\hline Discordo totalmente & Nenhuma pessoa & $0 \%$ \\
\hline Discordo & 1 pessoa & $5 \%$ \\
\hline Discordo Parcialmente & 1 pessoa & $5 \%$ \\
\hline
\end{tabular}

Fonte: Dados da pesquisa, 2015.

O quadro de número quatro questiona sobre o tempo que os alunos com deficiência levam para realizar suas atividades, se demoram mais que alunos "normais". Aqui a grande maioria, 66\% das pessoas, respondeu que concorda que os alunos com algum tipo de deficiência demoram mais para aprender, 9,5\% concordam totalmente e 14\% concordam parcialmente, mas 5\% das pessoas discordam e também $5 \%$ discordam parcialmente.

De acordo com pesquisa apresentada pelo Ministério da Educação (MEC), em 2002, a criança com deficiência múltipla é o educando com necessidade mais acentuada, já que a inclusão pode trazer benefícios incontestáveis para o desenvolvimento. (RAMOS, s/d p.10).

Quadro 5 - Considera um processo de ensinar e interagir com alunos com surdocegueira possível para todos os educadores?

\begin{tabular}{|l|l|l|}
\hline Código & Número de respostas & Porcentagem \% \\
\hline Concordo totalmente & Nenhuma pessoa & $0 \%$ \\
\hline Concordo & 4 pessoas & $19 \%$ \\
\hline Concordo parcialmente & 12 pessoas & $57 \%$ \\
\hline Discordo totalmente & 2 pessoas & $9,5 \%$ \\
\hline Discordo & 2 pessoas & $9.5 \%$ \\
\hline Discordo Parcialmente & 1 pessoa & $5 \%$ \\
\hline
\end{tabular}

Fonte: Dados da pesquisa, 2015.

O quinto quadro nos traz a informação que $57 \%$ dos educadores consideram o processo de ensinar e interagir com o aluno surdocego possível a todos os educadores, $19 \%$ concorda com a ideia, mas $9,5 \%$ discordam totalmente e também $9,5 \%$ somente discordam e 5\% discordam parcialmente, acreditando que nem todos os profissionais têm a possibilidade de atuar com os alunos surdocegos.

As principais necessidades específicas para apoiar a inclusão de pessoas com surdocegueira são: comunicação, orientação, mobilidade e um parceiro efetivo e significativo para a comunicação, que são os guias-intérpretes e os instrutores mediadores (MAIA, 2010 p. 11). 
http://dx.doi.org/10.5902/1984686X24891

Quadro 6 - Em sua unidade escolar são atendidos alunos com diferentes deficiências. Estes alunos são bem acolhidos, aceitos e interagem tanto com seus pares como com a equipe escolar?

\begin{tabular}{|l|l|l|}
\hline Código & Número de respostas & Porcentagem \% \\
\hline Concordo totalmente & 5 pessoas & $24 \%$ \\
\hline Concordo & 8 pessoas & $38 \%$ \\
\hline Concordo parcialmente & 6 pessoas & $28.5 \%$ \\
\hline Discordo totalmente & Nenhuma resposta & $0 \%$ \\
\hline Discordo & 1 pessoa & $5 \%$ \\
\hline Discordo Parcialmente & Nenhuma resposta & $0 \%$ \\
\hline
\end{tabular}

Fonte: Dados da pesquisa, 2015.

No sexto quadro diante da interação entre aluno surdocego e profissionais e também os seus pares pôde-se observar que $24 \%$ das pessoas concordam totalmente que existe este entrosamento, $38 \%$ concordam e $28,5 \%$ das pessoas que responderam o questionário concordam parcialmente. Somente $5 \%$ das pessoas discordaram em relação esta resposta.

A inclusão e o desenvolvimento das habilidades das crianças [...] dependem da possibilidade de interação, acolhimento e socialização que são proporcionados pela escola, pais e comunidade (MAIA, 2010, p.12).

Quadro 7- Entre as deficiências que atendemos nesta unidade escolar, está a deficiência surdocegueira. Todos os profissionais estão capacitados para lidar com a deficiência na sala de aula?

\begin{tabular}{|l|l|l|}
\hline Código & Número de respostas & Porcentagem \% \\
\hline Concordo totalmente & Nenhuma resposta & $0 \%$ \\
\hline Concordo & 1 pessoa & $5 \%$ \\
\hline Concordo parcialmente & Nenhuma resposta & $0 \%$ \\
\hline Discordo totalmente & 4 pessoas & $19 \%$ \\
\hline Discordo & 15 pessoas & $71 \%$ \\
\hline Discordo Parcialmente & 1 pessoa & $5 \%$ \\
\hline
\end{tabular}

Fonte: Dados da pesquisa, 2015.

No sétimo quadro observamos que os profissionais da unidade escolar pesquisada não se sentem capacitados para atuar com os alunos deficientes, sendo assim somente $5 \%$ dos profissionais acreditam estar aptos para atuar na área das deficiências, os demais $71 \%$ discordam, mostrando que não se encontram capacitados e $19 \%$ discordam totalmente e $5 \%$ discordam parcialmente.

No atendimento educacional, utilizamos o sistema de tutoramento, no qual existe um mediador em quem a criança confia para guiar as ações com o objetivo de estabelecer um meio de comunicação do aluno com o seu ambiente (CONCEIÇÃO, 2010, p.12). deficiência?

Quadro 8 - Os profissionais da educação alteram seu planejamento quando recebem um aluno com

\begin{tabular}{|l|l|l|}
\hline Código & Número de respostas & Porcentagem \% \\
\hline Concordo totalmente & Nenhuma resposta & $0 \%$ \\
\hline
\end{tabular}


http://dx.doi.org/10.5902/1984686X24891

\begin{tabular}{|l|l|l|}
\hline Concordo & 5 pessoas & $24 \%$ \\
\hline Concordo parcialmente & 8 pessoas & $38 \%$ \\
\hline Discordo totalmente & 1 pessoa & $5 \%$ \\
\hline Discordo & 4 pessoas & $19 \%$ \\
\hline Discordo Parcialmente & 3 pessoas & $14 \%$ \\
\hline
\end{tabular}

Fonte: Dados da pesquisa, 2015.

No oitavo quadro pôde-se constatar que ainda há resistência em atender alunos com deficiência, pois somente $38 \%$ dos profissionais (ainda que parcialmente) alteram o seu planejamento, quando recebem um aluno com deficiência, mas já há uma boa expectativa, pois $24 \%$ dos profissionais concordam que alteram os seus planejamentos. $5 \%$ discordam totalmente e $19 \%$ discordam, mostrando um número consideravelmente alto para os profissionais que não modificam os planejamentos de aula e 14\% discordam parcialmente. Liberato (s/d, p.10) relata que "o trabalho com essa criança me mostrou que a adaptação ao conteúdo escolar é realizada pelo próprio aluno. Tive que recriar minhas praticas, mudar minhas concepções e rever o meu papel, além de valorizar e reconhecer as diferenças".

As questões de número 09 e 10 são abertas e solicitaram aos pesquisados que contribuíssem com nossa pesquisa, respondendo aos seguintes questionamentos:

Questão 9- Quais são as habilidades que devemos desenvolver no caso de alunos surdocegos?

Diante do questionamento oito profissionais responderam que para se trabalhar com um aluno surdocego é necessário desenvolver habilidades de aceitação, conversação, socialização, interação com colegas, professores e toda a equipe escolar, independência, segurança, locomoção comunicação, estimulação, exploração de ambientes por fontes sonoras, tátil e contato físico, curiosidade e interesse por parte do aluno e o profissional deve acreditar nele. Falam também que os alunos com surdocegueira tem o mesmo direito à aprendizagem que os demais, só que o desenvolvimento de aprendizagem será de uma maneira diferente. Mas alertam que para que isso possa ser realizado, o profissional deve ter uma ampla formação e ser comprometido em ensinar, porque o conhecimento é indispensável para haver qualidade no desenvolvimento e aprendizagem dos alunos com deficiência. Porém ainda encontramos profissionais que se assustam e criam certa resistência ao saber que vão receber um aluno com deficiência em sua turma por não estarem preparados para atendê-los. Por esse motivo os profissionais devem participar de cursos de aperfeiçoamento para se prepararem e elaborarem planejamentos que venham a ajudar o aluno e a turma no processo de inclusão. 
Questão 10- Em sua opinião, como é atendido o aluno com surdocegueira na Escola Municipal Professor José Boeing? Quais são as dificuldades e conquistas?

Diante da análise das respostas, pudemos perceber a satisfação dos profissionais da instituição perante ao atendimento do aluno surdocego realizado, em que quinze (15) expressam satisfação diante das conquistas. Observa-se o grande interesse, acompanhamento e busca de formação, conhecimento e técnicas dos profissionais atuantes com o aluno, o que comprova o comprometimento deste com a "Educação para todos", a dedicação da família, bem como o contato com os profissionais habilitados da Fundação Catarinense de Educação Especial que estão em constante contato com os professores do aluno e gestão da escola. Também podemos citar as grandes conquistas como fala, socialização com escola e desenvolvimento de amizades (interação), interesse em aprender, amadurecimento neste período e autonomia. O aluno expressa alegria no ambiente escolar, e também foi citada a evolução em seu processo de locomoção.

Já as dificuldades são muitas por ser um caso específico e raro. Há falta de preparo de todo o corpo docente para trabalhar com alunos com necessidades educacionais especiais. Logo, o professor da turma, muitas vezes, não sabe como adequar o seu trabalho para incluir o aluno em todas as atividades. Outra dificuldade citada foi em relação à troca de professores a cada ano o que não dá continuidade ao trabalho realizado com aluno. Dificuldades como a falta de estrutura física em alguns locais na escola, a falta de recursos/materiais adequados e adaptados disponíveis para auxiliar o aluno, sendo necessário que a professora use materiais existentes ou, na maioria das vezes, confecciona-os. Os transportes escolares não estão adequados às suas necessidades. Um dos maiores e mais relevantes posicionamentos dos profissionais foi quanto à falta de formação específica na área das deficiências para todos os profissionais da instituição, alegando que há dificuldade de relacionamento, dificultando até mesmo o processo de inclusão, quando o profissional não sabe como reagir perante um aluno deficiente.

\section{Considerações Finais}

O processo de inclusão não acontece somente para as pessoas com deficiência. Deve ser um processo natural de inserir todas as camadas sociais que, historicamente, ficaram excluídas, por isso o termo surgiu com força de lei. A inclusão é um processo que tem como objetivo a "Educação para todos" sejam estes deficientes ou não. É direito, não apenas obrigação de aceitar. 
Ao construir o referencial teórico que sustenta a pesquisa, traduzimos neste estudo parte dos objetivos elencados para a pesquisa, pois percorremos a trajetória histórica do processo de inclusão bem como conceituamos as deficiências, enfatizando a surdocegueira, objeto deste trabalho.

Com o relato da historicidade do sujeito pesquisado, caracterizamos como podem ocorrer deficiências múltiplas e de que forma é possível inseri-los de direito na escola regular.

Com a análise dos resultados da pesquisa aplicada aos docentes da Escola Municipal Professor José Boeing, constatou-se os avanços e as limitações destes profissionais em relação à inclusão de um aluno surdocego. A inclusão é um direito inalienável de todo ser humano, portanto, é necessário que as políticas públicas sejam incluídas e que os docentes aceitem a prática da inclusão como prerrogativa legal, mas, acima de tudo, entendam que o deficiente é um ser humano e que precisa ser desenvolvido a partir de suas humanidades. Isto é o que podemos chamar de princípio da dignidade humana.

Outro aspecto pontuado nos objetivos está relacionado à questão do planejamento elaborado pelo docente e que precisa ser construído no sentido de incluir todos, indistintamente. Neste aspecto ainda constata-se certa resistência, o olhar e a formação docente ainda estão focados para uma docência para os "inteligentes" "os normais".

Diante de todo o processo de estudo e pesquisa, pode-se perceber que o processo de inclusão ainda não acontece de forma integral, mas podemos perceber uma maior preocupação do corpo docente em sanar as dúvidas.

A pesquisa apontou também para a necessidade de formação continuada dos docentes no que se refere à inclusão e ao atendimento de alunos com deficiências múltiplas na rede municipal de ensino de Rio Fortuna- SC. Esta sugestão já foi dada pela pesquisadora e já está programada para o início do próximo ano letivo.

\section{Referências}

BAPTISTA, Caroline. Recebendo Alunos com Deficiência. Revista: Mundo da Inclusão. Minuano Cultural. s/d.

BOSCO, Ismênia Carolina Mota Gomes; MESQUITA, Sandra Regina Stanziani Higino e MAIA Shirley Rodrigues. A Educação Especial na Perspectiva da Inclusão Escolar. Surdocegueira e Deficiência Múltipla. Brasília: Ministério da Educação, Secretaria de Educação Especial ; [Fortaleza] : Universidade Federal do Ceará, 2010. 
BRASIL, Lei de Diretrizes e Bases - LDB. LEI № 4.024, DE 20 DE DEZEMBRO DE 1961. Disponível em: http://www.planalto.gov.br/ccivil_03/leis/L4024.htm. Acesso em 15/05/15.

BRASIL. Ministério da Educação e do Desporto. Secretaria de Educação Fundamental. Referencial curricular nacional para a educação infantil. Ministério da Educação e do Desporto, Secretaria de Educação Fundamental. - Brasília: MEC/SEF, 1998. 3v.:il.

BRASIL. LEI № 10.436, DE 24 DE ABRIL DE 2002. Disponível em: http://www.camara.gov.br/sileg/integras/821803.pdf. Acesso em 12/06/15.

\section{BRASIL. Política Nacional de Educação Especial na Perspectiva da Educação Inclusiva, $\quad$ Brasil, $2002 . \quad$ Disponível http://peei.mec.gov.br/arquivos/politica_nacional_educacao_especial.pdf. Acesso em 13/04/15.}

BRASIL. DECRETO № $\mathbf{5 . 2 9 6}$ de 2 de dezembro de 2004. Presidência da república. Casa civil- subchefia para assuntos Jurídicos. Brasília, 2004.

BRASIL. Política Nacional de Educação Especial na Perspectiva de Educação Inclusiva. Documento elaborado pelo Grupo de Trabalho Nomeado pela Portaria no 555, de junho de 2007, prorrogada pela Portaria nº 948, de 09 de outubro de 2007, MEC/SEESP.

BRUNO, Marilda Moraes Garcia. Deficiência Visual. Reflexão sobre a Prática Pedagógica. São Paulo: Laramara,1997.

BRUNO, Marilda Moraes Garcia. Educação Infantil: saberes e práticas da inclusão: Introdução. Brasília: MEC, Secretaria de Educação Especial, 2006. 45p.: il.

CONCEIÇÃO, Carla Patrícia Ferreira da. Atendimento Educacional do Aluno com Surdocegueira. In: Revista: Ciranda da Inclusão. Ciranda Cultural, 2010.

GODÓI, Ana Maria de. Educação Infantil: Saberes e Práticas da Inclusão: dificuldades acentuadas de aprendizagem: Deficiências Múltiplas. 4 ed. Brasília: MEC, Secretaria de Educação Especial, 2006.

GODÓI, Ana Maria de. Métodos e técnicas de pesquisa social. 6 ed. São Paulo: Atlas, 2008.

LAGATI, S. Deaf-Blind or Deafblind International Perspectives on Terminology.1995 Tradução: Laura L. M. Anccilotto. São Paulo: Projeto Ahimsa/Hilton Perkins, 2002.

LAKATOS, Eva Maria e MARCONI, Marina de Andrade. Fundamentos de metodologia científica. 7 ed. São Paulo: Atlas, 2010.

LIBERATO, Dulcilene Almeida da Silva. Uma experiência que deu certo. Revista: Mundo da Inclusão. Minuano Cultural, s/d.

LIMA, Daisy Maria Collet de Araújo. Educação Infantil: saberes e práticas da inclusão: Dificuldades de comunicação e sinalização: surdez. 4ed. Secretaria do Estado da Educação do Distrito Federal - Brasília: MEC, 2006. 
LIMA, Priscila Augusta. Educação Inclusiva e Igualdade Social. São Paulo: Avercamp, 2006. 176p.

MAIA, Shirlei Rodrigues. Surdocegueira: Uma condição única. Revista: Ciranda da Inclusão. Ciranda Cultural. 2010

McINNES. Deafblindness: a unique disability. In: McINNES, John M. (Org.) Aguide to planning and support for individuaals who are deafblind. Canadá: University of Toronto Press Incorporated, 1999. TREFFY, J. A. Deaf-blind infants and children: a developmental guide. Trad. Mary Inês R. M. Loschiavo. São Paulo: AHIMSA, 1991.

RAMOS, Rossana. Inclusão na Prática: estratégias eficazes para educação inclusiva 2ed. São Paulo: Summus, 2010.

RAMOS, Deise. Deficiência Múltipla- Rotina Escolar. Ajuda no desenvolvimento. Revista: Mundo da inclusão. s/d.

SÁ, Elizabet Dias de. CAMPOS, Izilda Maria de. SILVA, Myriam Beatriz Campolina. Atendimento Educacional Especializado- Deficiência Visual. SEESP/SEED/MEC. Brasília, 2007.

SANTA CATARINA. Educação Especial e Aprendizagem - Educação Especial as Variadas Formas de Olhar a Diferença. Caderno Pedagógico- Udesc. 2 ed. Florianópolis, 2003.

SANTA CATARINA. RESOLUÇÃO №112, 12 de Janeiro de 2004. Estado de Santa Catarina, Conselho do estado de Santa Catarina, 2004.

SANTA CATARINA. Resolução № 112 do Conselho Estadual de Santa Catarina de 12 de dezembro de 2006. Florianópolis, 2006.

VARGAS, Gárdia. BECHE, Rose Clér Estivalete. SILVA, Solange Cristina da. Educação Especial e Aprendizagem. Pedagogia a distância-UDESC. Florianópolis, 2003.

\section{Correspondência}

Luiza Liene Bressan - Fundação Educacional Barriga Verde, Centro Universitário Barriga Verde. Rua Pe. João Leonir D'Alaba. Murialdo. CEP: 88870-000. Orleans, Santa Catarina, Brasil.

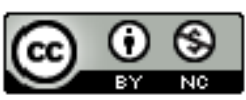

This work is licensed under a Creative Commons Attribution-NonCommercial 4.0 International (CC BY-NC 4.0) 